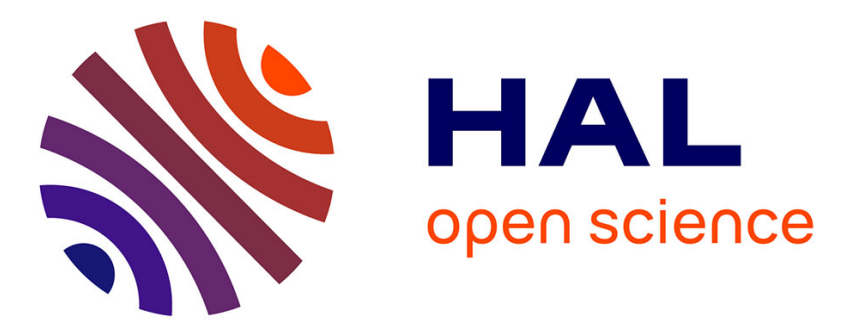

\title{
Propionibacterium acnes populations involved in deep pathological samples and their dynamics along the cardiac surgical pathway
}

Sara Romano-Bertrand, B Beretta, H. Jean-Pierre, Jean-Marc Frapier, Brigitte Calvet, Sylvie Parer, Estelle Jumas-Bilak

\section{To cite this version:}

Sara Romano-Bertrand, B Beretta, H. Jean-Pierre, Jean-Marc Frapier, Brigitte Calvet, et al.. Propionibacterium acnes populations involved in deep pathological samples and their dynamics along the cardiac surgical pathway. European Journal of Clinical Microbiology and Infectious Diseases, 2015, 34 (2), pp.287 - 301. 10.1007/s10096-014-2228-2 . hal-01762810

\section{HAL Id: hal-01762810 \\ https://hal.umontpellier.fr/hal-01762810}

Submitted on 8 Nov 2018

HAL is a multi-disciplinary open access archive for the deposit and dissemination of scientific research documents, whether they are published or not. The documents may come from teaching and research institutions in France or abroad, or from public or private research centers.
L'archive ouverte pluridisciplinaire HAL, est destinée au dépôt et à la diffusion de documents scientifiques de niveau recherche, publiés ou non, émanant des établissements d'enseignement et de recherche français ou étrangers, des laboratoires publics ou privés. 


\title{
Propionibacterium acnes populations involved in deep pathological samples and their dynamics along the cardiac surgical pathway
}

\author{
S. Romano-Bertrand • M. Beretta • H. Jean-Pierre • \\ J.-M. Frapier • B. Calvet • S. Parer • E. Jumas-Bilak
}

\begin{abstract}
Propionibacterium acnes belongs to the normal skin microbiota, but it is also responsible for acne vulgaris and causes serious infections such as endocarditis and surgical site infections (SSI). The P. acnes population is structured into phylogenetic groups, with phylotype I being associated with acne. Herein, we explore the link between phylotypes and clinical origins in a collection of $P$. acnes isolated from different body sites, involved in deep infections or healthcareassociated infections (HAI), with particular emphasis on strains from cardiac SSI. Cardiac SSI have been further studied in terms of $P$. acnes population dynamics during the care pathway. The recA and tly genes phylotypes were compared to hemolytic behavior, susceptibility to antimicrobial agents, and clinical origins. An original approach of $r e c A$ polymerase chain reaction temporal temperature gel electrophoresis (PCR-TTGE) was developed and applied for the direct identification of $P$. acnes phylotypes in surgical samples, in order
\end{abstract}

S. Romano-Bertrand $\cdot$ M. Beretta $\cdot$ H. Jean-Pierre $\cdot$ E. Jumas-Bilak UMR 5119 ECOSYM, Equipe Pathogènes et Environnements, U.F.R. des Sciences Pharmaceutiques et Biologiques, Université Montpellier 1, 15, Avenue Charles Flahault, BP 14491,

34093 Montpellier Cedex 5, France

S. Romano-Bertrand $(\bowtie) \cdot$ E. Jumas-Bilak

Hospital Hygiene and Infection Control Team, University Hospital of Montpellier, Montpellier, France

e-mail: sara.romano-bertrand@univ-montp1.fr

H. Jean-Pierre $\cdot S$. Parer

Bacteriology Laboratory, University Hospital of Montpellier, Montpellier, France

J.-M. Frapier

Cardio-thoracic Surgery Unit, University Hospital of Montpellier, Montpellier, France

B. Calvet

Cardio-thoracic Intensive Care Unit, University Hospital of

Montpellier, Montpellier, France to assess their temporal dynamics during the surgical course. Our results underlined the preferential involvement of IA-2/IB and II phylogroups in HAI and SSI. Unlike IA and II, type IA2/IB presented a gradual increase with the depth of sampling in the peroperative phase of cardiac surgery. Phylotypes IA and IA-2/IB were both predominant in scar tissues and on postoperative skin, suggesting a specific predisposition to recolonize skin. Particular association of the phylotype IA-2/ IB with SSI and its propensity to colonize wounds in cardiac surgery was observed. We assumed that the follow-up of $P$. acnes phylotypes during pathological processes could give new clues for $P$. acnes pathogenicity.

\section{Introduction}

Propionibacterium acnes is an anaerobic Gram-positive bacillus member of the human microbiota mainly on skin [1], but also in the oral cavity, and digestive and genital tracts [2]. In clinical samples, $P$. acnes is often overlooked as a contaminant and is underestimated due to its growth requirements [3-5]. However, $P$. acnes can produce putative virulence factors involved in inflammation processes [4], as observed in acne vulgaris [5] and other inflammatory pathologies, such as sarcoidosis [6], or potentially in prostatic pathologies [7]. $P$. acnes can also cause severe deep infections like endocarditis [8-10] and surgical site infections (SSI) in orthopedic [11, 12], cardiac [13, 14], or neurological surgeries [15].

Metagenomics [16] and comparative genomics [17] showed strain variations supporting the existence of specific $P$. acnes subpopulations. The strain HL096PA1 causing severe acne displayed a plasmid encoding adhesion factors and a high amount of pseudogenes, suggesting its adaptation to pathogenic behavior in a narrow niche [18]. Moreover, population genetics indicated the roles of distinct lineages of $P$. acnes in different diseases. In this context, several 
multilocus sequence typing (MLST) schemes, including from 3 to 9 loci according to studies, were proposed. They identified three main distinct phylotypes, named I, II, and III [19-23]. Phylotype I is subdivided into groups IA (subdivided into IA-1 and IA-2), IB, and IC [23, 24], but recombination events occur between IA-2 and IB groups, leading to misidentification of these subtypes [25]. The genes recA (recombinase A) and tly (putative hemolysin) were widely used in MLST schemes because they presented satisfactory discriminative power among the three phylotypes I, II, and III $[23,26]$. The association of $r e c A$ and tly allowed the identification of IA-1 but not the separation of IA-2 from IB [25]. Moreover, recA structuration is correlated to antigens, cell wall sugar, and matrix-assisted laser desorption/ionization time-of-flight (MALDI-TOF) types [27].

Phylotype I appeared to be the most prevalent in the whole population of $P$. acnes and gathered mainly isolates from acne and healthy skin [23, 24]. Division IA comprised the majority of isolates from inflammatory acne lesions [28]. It included the epidemic clone ST18 (=eST1) and its descendants in the IA-1 group [22, 25], which were never detected in healthy skin [20].

Besides phylotype IA and acne, links between genetic group and pathogenic behavior were not fully meaningful. Isolates of phylotypes II and III were described as originating mainly from healthcare-associated infections (HAI) [19], but this association was not exclusive because type I strains were also involved in HAI [20]. Types IB and II were often encountered in prostatectomy specimens from cancer [29], without prediction of infection or disease [30]. Similarly, phylotypes IB and II were often detected during revising prosthetic surgeries, but their presence did not differentiate infection from colonization [11]. Despite an unclear association between a particular genetic group and a specific pathogenic behavior in some cases, the published data lend support to the view that pathogenic versus truly commensal lineages of P. acnes may exist [25]. The determination of relationships between lineages and infections is likely to have important therapeutic and diagnostic implications [25].

In cardiac surgery, $P$. acnes is the third most prevalent bacterium in deep SSI [13, 31, 32], making it important to consider. A previous study based on universal $16 \mathrm{~S}$ polymerase chain reaction temporal temperature gel electrophoresis (PCRTTGE) describing the dynamic of bacterial communities in cardiac surgery wounds showed high rates of Propionibacterium spp. at different stages of patients' hospitalization [31]. However, no study has yet described the phylotypes involved in cardiac SSI, preventing rare isolates from SSI being included in the currently available MLST studies [19, 25].

The purpose of this study was to explore the links between the main phylotypes based on recA and tly sequencing and clinical origins, hemolytic behavior, and resistance in a collection of $P$. acnes involved in deep infections or HAI, with particular emphasis on strains from cardiac SSI. Based on the
recA phylogeny, an original culture-independent method was applied for the direct identification of $P$. acnes phylotypes involved in cardiac surgical samples in order to assess their dynamics during the surgical pathway of the patients.

\section{Materials and methods}

Propionibacterium acnes isolates, culture conditions, antibiotic susceptibilities, and hemolysis test

Ninety-nine $P$. acnes clinical isolates collected from different infectious sites between May 2011 and March 2013 at the Hospital of Montpellier (France) were analyzed (Table 1). The isolates were included considering at least one of the following criteria: (i) isolation in normally sterile sites, (ii) isolation in deep infectious processes, (iii) antimicrobial assay on the isolate for therapeutic purposes, (iv) prescription of antimicrobials targeted against $P$. acnes. Among the 99 strains, 27 were isolated from cardiothoracic samples (including 19 from cardiac SSI). Hemolysis tests were performed by culture on nutritive medium supplemented with $5 \%$ sheep blood (COS Agar, bioMérieux, France) at $37{ }^{\circ} \mathrm{C}$ in an anaerobic atmosphere. The degree of hemolysis was assessed after $72 \mathrm{~h}$ of culture and noted negative if absent, weak if present but light or moderate, and strong if important or total. Antibiotic susceptibilities were tested for cefamandole, vancomycin, and clindamycin by an agar diffusion assay (members of the Société Française de Microbiologie committee, 2003).

\section{Surgical samples and ethic statements}

Surgical site samples were obtained from 14 patients undergoing cardiac surgery at the Cardio-thoracic Surgery Unit of Montpellier University Hospital (France). They were collected superficially and deeply at the different steps of hospitalization (before hospitalization, during the surgical procedure, during postoperative hospitalization, and 3 months after discharge). Primary human materials used in this study were collected on sterile cotton swabs as performed for the routine clinical diagnostic process without change in the surgical procedures or nursing care. Each patient included gave oral informed consent. The study proposal was approved by the ethical committee of our institution: Comité de Protection des Personnes Sud Méditerranée IV, NID - RCB: 2011-A00078-33.

\section{DNA extraction and PCR amplification}

DNA was extracted from colonies or from surgical samples on cotton swabs by an enzymatic method (MasterPure Gram Positive DNA Purification Kit, Epicentre, France) and diluted at a final concentration of $50 \mathrm{ng} / \mu \mathrm{L}$. The $16 \mathrm{~S}$ rRNA gene was amplified using the primers HDA1f-HDA2r [31, 33]. The 
Table 1 Origins, genotype, and hemolytic capacity of the

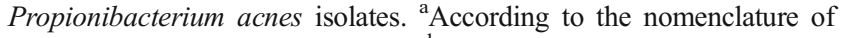
the http://pacnes.mlst.net/ database. ${ }^{\mathrm{b}}$ According to the nomenclature of the http://pubmlst.org/pacnes/ database. Allele numbers marked with an asterisk correspond to new alleles displaying $>99 \%$ identity in the sequence with the original allele. SSI surgical site infections, STM skintissue-muscle. $I B$ corresponded to IA-2/IB, the two types being undistinguishable by recA/tly typing

\begin{tabular}{|c|c|c|c|c|c|c|c|c|}
\hline Strains and origins & & & $\begin{array}{l}\text { recA } \\
\text { type }\end{array}$ & $\begin{array}{l}\text { tly } \\
\text { type }\end{array}$ & $\begin{array}{l}\text { recA allele } \\
(753 \mathrm{pb})\end{array}$ & $\begin{array}{l}\text { recA allele }{ }^{\mathrm{b}} \\
(463 \mathrm{pb})\end{array}$ & $\begin{array}{l}\text { tly allele }{ }^{\mathrm{b}} \\
(777 \mathrm{pb})\end{array}$ & Hemolysis \\
\hline \multirow{27}{*}{$\begin{array}{l}\text { Cardiothoracic isolates } \\
(n=27, \text { including cardiac } \\
\text { SSI isolates, } n=19)\end{array}$} & PA15 & Purulent effusion from sternal wound & II & II & 6 & 2 & 10 & - \\
\hline & PA23 & Sternal wound & IB & IB & 2 & 1 & 8 & ++ \\
\hline & PA38 & Sternal wound & IA & IA & 5 & 1 & 1 & +++ \\
\hline & PA54 & Heart defibrillator & IB & IB & 2 & 1 & 8 & ++ \\
\hline & PA74 & Pacemaker lodge & IA & IA & 5 & 1 & 1 & - \\
\hline & PA75 & Left ventricular pacemaker sensor & IA & IA & 5 & 1 & 1 & - \\
\hline & PA76 & Postoperative mediastinal hematoma & IB & IB & 2 & 1 & 8 & - \\
\hline & PA76b & & IB & IB & 2 & 1 & 8 & - \\
\hline & PA83 & Aortic valve & IB & IB & 2 & 1 & 8 & - \\
\hline & PA $83 b$ & & IB & IB & 2 & 1 & 8 & - \\
\hline & PA83t & & IB & IB & 2 & 1 & 8 & - \\
\hline & PA86 & Sternal wound & IA & IA & 5 & 1 & 1 & + \\
\hline & PA92 & Sternum & IA & IA & 5 & 1 & 1 & +++ \\
\hline & PA93 & Sternum & IA & IA & 5 & 1 & 1 & ++++ \\
\hline & PA94 & Sternal wound & IB & IB & 2 & 1 & 8 & ++ \\
\hline & PA95 & Purulent effusion from sternal wound & IB & IB & 2 & 1 & 8 & ++ \\
\hline & PA98 & Valve & II & II & 6 & 2 & 10 & - \\
\hline & PA99 & Pleural injury & IB & IB & 2 & 1 & 8 & +++ \\
\hline & PA 100 & Tricuspid valve & II & II & 6 & 2 & 10 & - \\
\hline & PA103 & Pacemaker & IA & IA & 5 & 1 & 1 & - \\
\hline & PA104 & Aortic ring & IB & IB & 2 & 1 & 8 & - \\
\hline & PA105 & Pacemaker lodge & IA & IA & 5 & 1 & 1 & ++++ \\
\hline & PA109 & Sternum & IB & IB & 2 & 1 & 8 & +++ \\
\hline & PA110 & Pacemaker effusion & IA & IA & 5 & 1 & 1 & - \\
\hline & PA113 & Pacemaker lodge & IB & IB & 2 & 1 & 8 & +++ \\
\hline & PA114 & Sternal wound & IA & IA & 5 & 1 & 1 & ++++ \\
\hline & PA115 & Sternal wound effusion & IB & IB & 2 & 1 & 8 & ++ \\
\hline \multirow{14}{*}{$\begin{array}{l}\text { Postoperative orthopedic } \\
\text { isolates }(n=14)\end{array}$} & PA14 & Shoulder bladder & IB & IB & 2 & 1 & 8 & + \\
\hline & PA19 & Knee prosthesis & IB & IB & 2 & 1 & 8 & + \\
\hline & PA28 & Femoral biopsy & IA & IA & 5 & 1 & 1 & ++ \\
\hline & PA31 & Femoral shaft & IA & IA & 5 & 1 & 1 & - \\
\hline & PA31b & Osteoarticular capsule & II & II & 6 & 2 & 10 & - \\
\hline & PA64 & Sacrum bone & IB & IB & 2 & 1 & 8 & ++ \\
\hline & PA70 & Superficial wound infection (osteoarticular) & IB & IB & 2 & 1 & 8 & ++ \\
\hline & PA72 & Knee synovial fluid & IB & IB & 2 & 1 & 8 & +++ \\
\hline & PA73 & Hip hematoma & IB & IB & 2 & 1 & 8 & +++ \\
\hline & PA85 & Spondylitis & II & II & 6 & 2 & 10 & - \\
\hline & PA87 & Left humerus & III & III & 9 & 4 & 12 & - \\
\hline & PA 88 & Left humerus prosthesis & IB & IB & 2 & 1 & 8 & + \\
\hline & PA89 & Left humerus prosthesis & IB & IB & 2 & 1 & 8 & ++ \\
\hline & PA90 & Left humerus prosthesis & II & IB & $8 *$ & 2 & 8 & - \\
\hline \multirow{4}{*}{$\begin{array}{l}\text { Oropharyngeal } \\
\quad \text { isolates }(n=12)\end{array}$} & PA6 & Left maxillary sinus & IA & IA & 5 & 1 & 2 & - \\
\hline & PA17 & Outer ear & IA & IA & 5 & 1 & 1 & +++ \\
\hline & PA18 & Outer ear & IB & IB & 2 & 1 & 8 & +++ \\
\hline & PA45 & Infected skin of skull & IA & IA & 5 & 1 & 1 & ++++ \\
\hline
\end{tabular}


Table 1 (continued)

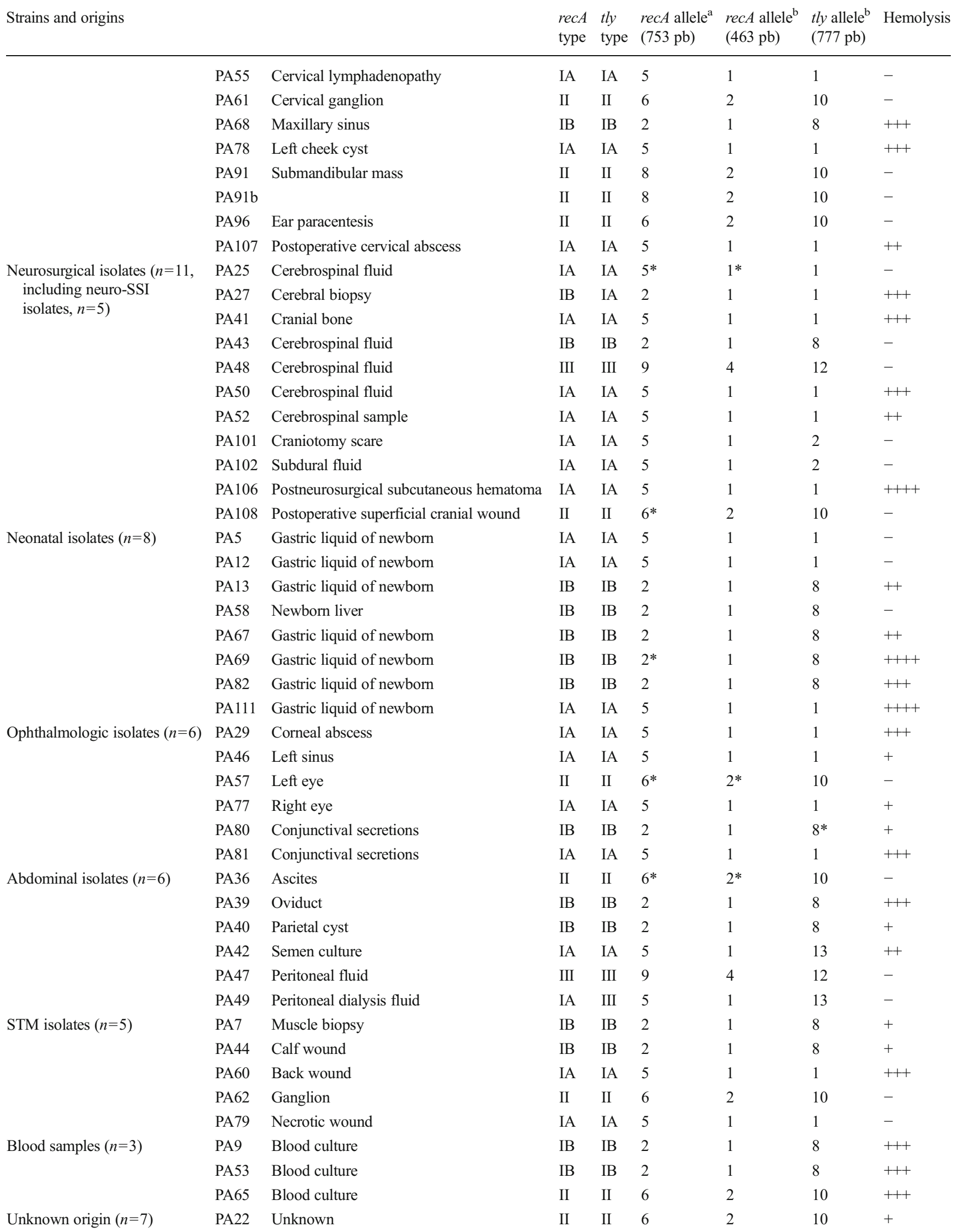


Table 1 (continued)

\begin{tabular}{|c|c|c|c|c|c|c|c|c|}
\hline \multicolumn{3}{|l|}{ Strains and origins } & \multirow{2}{*}{$\begin{array}{l}\text { recA } \\
\text { type }\end{array}$} & \multirow{2}{*}{$\begin{array}{l}\begin{array}{l}\text { tly } \\
\text { type }\end{array} \\
\text { IB }\end{array}$} & \multirow{2}{*}{$\begin{array}{l}\begin{array}{l}\text { recA } \text { allele }^{\mathrm{a}} \\
(753 \mathrm{pb})\end{array} \\
2\end{array}$} & \multirow{2}{*}{$\begin{array}{l}\text { recA allele }{ }^{\mathrm{b}} \\
(463 \mathrm{pb})\end{array}$} & \multirow{2}{*}{$\begin{array}{l}\begin{array}{l}t^{\prime l y} \text { allele }^{\mathrm{b}} \\
(777 \mathrm{pb})\end{array} \\
8\end{array}$} & \multirow{2}{*}{$\begin{array}{l}\text { Hemolysis } \\
++\end{array}$} \\
\hline & PA32 & Unknown & & & & & & \\
\hline & PA33 & Unknown & IB & IB & 2 & 1 & 8 & ++ \\
\hline & PA34 & Unknown & IB & IB & 2 & 1 & 8 & +++ \\
\hline & PA51 & Unknown & II & II & 6 & 2 & 10 & - \\
\hline & PA56 & Unknown & II & II & 6 & 2 & 10 & - \\
\hline & PA84 & Unknown & II & II & 8 & 2 & 10 & - \\
\hline
\end{tabular}

recA and tly genes were amplified by the primers PAR-1 (5'AGCTCGGTGGGGTTCTCTCATC-3') and PAR-2 (5'GCTTCCTCATACCACTGGTCATC- $\left.3^{\prime}\right)$ and PAT-1 (5'CAGGACGTGATGGCAATGCGA-3') and PAT-2 (5'TCGTTCACAAGACCACAGTAGC-3'), respectively [24].

A nested PCR approach was needed because of the low bacterial load in surgical samples $\left(<10^{3} \mathrm{UFC} /\right.$ tube, assessed by $16 \mathrm{~S}$ rRNA gene-based PCR as previously described [31]). The recA nested PCR approach consisted of a preamplification (with primers PAR-1 and PAR-2), followed by a second amplification of a 333-pb fragment overlapping the terminal region of the $r e c A$ gene, using the primers PR264-GC (corresponding to the primer PR264 5'-GCAGGCAGAGTT TGACATCC-3' [30] with a "GC clamp" rich in GC added at the 5- extremity) and PAR-2. The PCR mixture of $50 \mu \mathrm{L}$ consisted of $1 \mu \mathrm{L}$ of DNA extract, $200 \mathrm{nM}$ of each primer, $200 \mathrm{mM}$ of each dNTP (Fermentas), and 2.5U FastStart Taq DNA Polymerase (Roche, France) in the appropriate reaction buffer containing $1.8 \mathrm{mM} \mathrm{MgCl}_{2}$. PCR conditions were an initial denaturation at $94{ }^{\circ} \mathrm{C}$ for $3 \mathrm{~min}$, followed by 35 cycles of $95^{\circ} \mathrm{C}$ for $1 \mathrm{~min}, 6{ }^{\circ} \mathrm{C}$ for $30 \mathrm{~s}$, and $72^{\circ} \mathrm{C}$ for $1 \mathrm{~min} 30 \mathrm{~s}$, and a final elongation at $72{ }^{\circ} \mathrm{C}$ for $10 \mathrm{~min}$.

Sequencing and phylogenetic analyses on $\boldsymbol{r e c} \boldsymbol{A}$ and $\boldsymbol{t} \boldsymbol{t} \boldsymbol{y}$ genes

Amplification products were sequenced using both primers PAR-1 and PAR-2 for $r e c A$ and forward primer PAT-1 for tly on an ABI 3730xl sequencer (Cogenics, France). Sequences were deposited in the GenBank database (accession numbers KJ572580 to KJ572777). Gene sequences were aligned using ClustalW [5] in order to determine the polymorphic positions. A number was attached to each sequence according to the recA and tly alleles available in the http://pacnes.mlst.net/ and http://pubmlst.org/pacnes/ databases. Phylogenetic trees were constructed based on maximum likelihood (ML) analysis using PhyML software (http://www.phylogeny.fr). The general time-reversible (GTR) model plus gamma distribution and invariant sites was used as the substitution model and bootstrap supports were computed after 100 reiterations. Reference $r e c A$ sequences for the types IA (AY642073), IB (AY642092), II (AY642090), and III (DQ672252) were included in the phylogenetic analysis [21,26]. An isolate that belonged to a clade containing a reference sequence was affiliated to the corresponding phylotype. Some tly and recA alleles in the subphylotype IA-2 are shared with phylotype IB [25]. Therefore, the phylotype IB will be named IA-2/IB in this study to avoid confusion.

rec $A$-based phylotyping by temporal temperature gel electrophoresis

TTGE migration was performed in the DCode Universal Mutation Detection System (Bio-Rad Laboratories). Gels contained $7 \%(\mathrm{w} / \mathrm{V})$ bisacrylamide $(37.5: 1), 7 \mathrm{M}$ urea, $40 \mathrm{ml} \mathrm{N}, \mathrm{N}, \mathrm{N} 9, \mathrm{~N} 9-$ tetramethylethylenediamine, and $0.1 \%$ $(\mathrm{w} / \mathrm{v})$ ammonium persulfate, and were run in 16 Tris acetate EDTA (TAE) buffer at $\mathrm{pH} 8.3$. The electrophoresis migration conditions were a pre-migration at $20 \mathrm{~V}$ for $15 \mathrm{~min}$ and a migration of $17.5 \mathrm{~h}$ at $53 \mathrm{~V}$ from an initial temperature of $67{ }^{\circ} \mathrm{C}$ to a final temperature of $70.5^{\circ} \mathrm{C}$ (increase of $0.2^{\circ} \mathrm{C}$ per hour). Bands were visualized on UV illuminator after gel incubation in an ethidium bromide bath. For band sequencing, gel slices excised with a sterile scalpel were washed twice in DNA-free water and DNA was eluted by an overnight incubation in $10 \mathrm{mM}$ Tris buffer $(\mathrm{pH} 8.5)$ at $37^{\circ} \mathrm{C}$. Amplification of the $5^{\prime}$-terminal recA region was performed using $1 \mu \mathrm{L}$ of band eluate and the primers PR264 without GC clamp and PAR-2 as previously described. PCR products were sequenced on an $\mathrm{ABI}$ 3730xl sequencer (Beckman Coulter Genomics) and compared to reference $r e c A$ sequences for phylotype affiliation.

\section{Results}

Phylogenetic structure of the $\boldsymbol{P}$. acnes clinical collection based on $\boldsymbol{r e c} \boldsymbol{A}$ and $\boldsymbol{t y} \boldsymbol{y}$ genes

The recA and tly consensus sequences of $1,119 \mathrm{bp}$ and $848 \mathrm{bp}$, respectively, were obtained for the 99 clinical isolates. Partial sequences were compared and numbered according to the MLST databases (Table 1). The alignment of the 1,119-bp 
recA sequences showed 22 polymorphic sites $(1.97 \%$ against $1.86 \%$ for the 753 -pb recA sequence used in the MLST databases), whereas the 848-bp tly sequences were more variable, with 39 polymorphic positions ( $4.6 \%$ against $4.12 \%$ for the 777-pb tly sequence used in the MLST databases). Phylogeny affiliated recA clades to phylotypes according to the reference sequences included in the analysis (Fig. 1). Tree topologies appeared robust and were globally congruent between recA and tly markers (Fig. 1), except for strains PA27, PA49, and PA90 (corresponding, respectively, to phylotypes IA-2/IB, IA and II in the recA tree, and to phylotypes IA, III, and IA-2/IB in the tly tree). These incongruences suggested recombination among phylotypes. It was noteworthy that the group PA6/PA101/PA102 was in phylotype IA in the rec $A$ tree and in a yet undescribed phylotype with a new allele related to allele 2 in the tly tree. The phylogenetic structure and isolates distribution did not significantly change when the concatenated sequence were analyzed. However, the tly undescribed clade (PA6, PA101, and PA102) was supported by a high bootstrap value in the concatenated tree, suggesting the emergence of a robust subpopulation (data not shown).

The clades IA and IA-2/IB gathered the majority of isolates (77/99) in both the recA and tly trees. However, some atypical

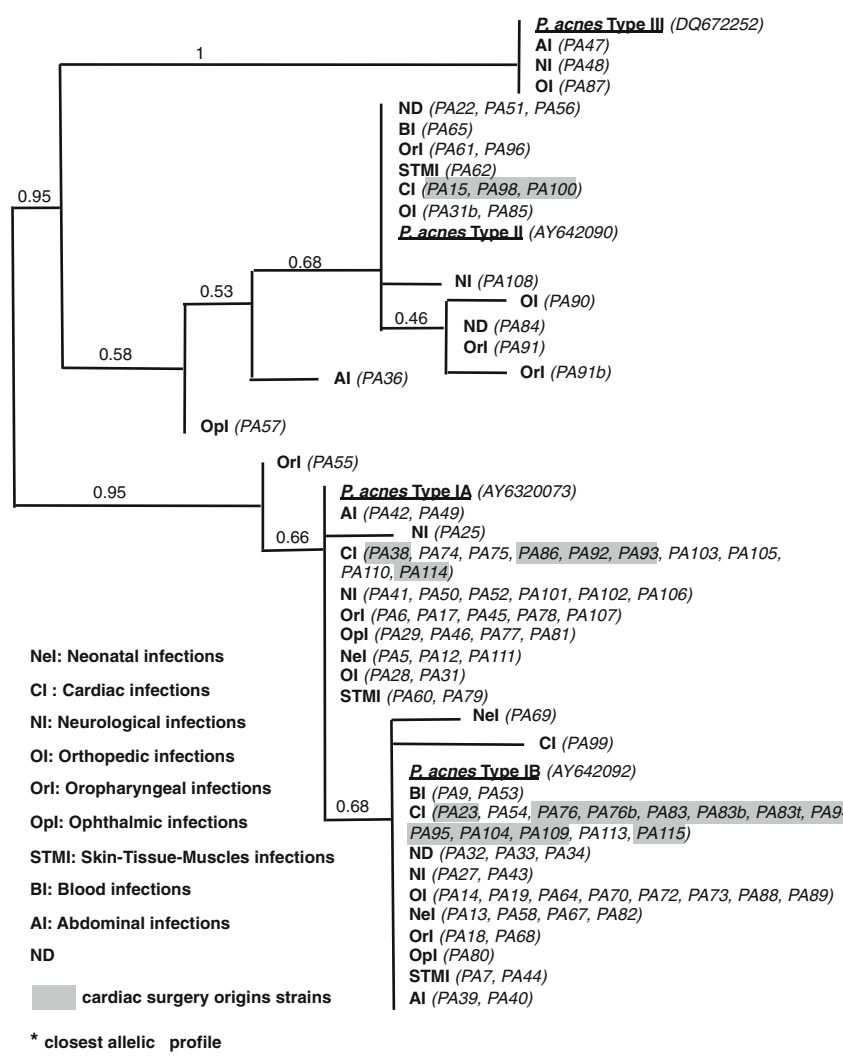

Fig. 1 Multilocus (ML) phylogenetic trees reconstructed from recA and tly sequences of Propionibacterium acnes isolates, left and right sides, respectively. The recA sequences of reference strains (underlined) are included for phylotype affiliation. For each branch, the corresponding allele is numbered according to the MLST scheme deposited in http:// isolates in each clade differed from the reference sequences and from the majority of isolates. Among them, PA25 and PA69 displayed undescribed new recA alleles. PA99, PA109, and PA73 had allelic affiliation in MLST, but their incongruent phylogenetic positions were due to mutations out of the region used for MLST, suggesting the emergence of new lineages in phylotype I by gene mutation rather than by gene exchange.

Phylotype II was less robust and displayed higher diversity in the recA tree. However, the majority of isolates $(n=12)$ were grouped with the reference sequences and corresponded to the recA allele 6 in the MLST scheme in http://pacnes.mlst. net/ (Fig. 1, left side). The other isolates $(n=7)$ were distributed in six branches supported by low bootstrap values, making their relative phylogenetic positions uncertain. They corresponded to alleles 6 and 8 , but were also related to new alleles in http://pacnes.mlst.net/. In the tly tree, phylotype II displayed low diversity and formed a robust clade (Fig. 1, right side) that fully matched tly allele 10 in MLST. Finally, phylotype III was the least represented in our collection $(n=3$ in the rec $A$ tree and $n=4$ in the tly tree), which displayed low variability and high robustness.

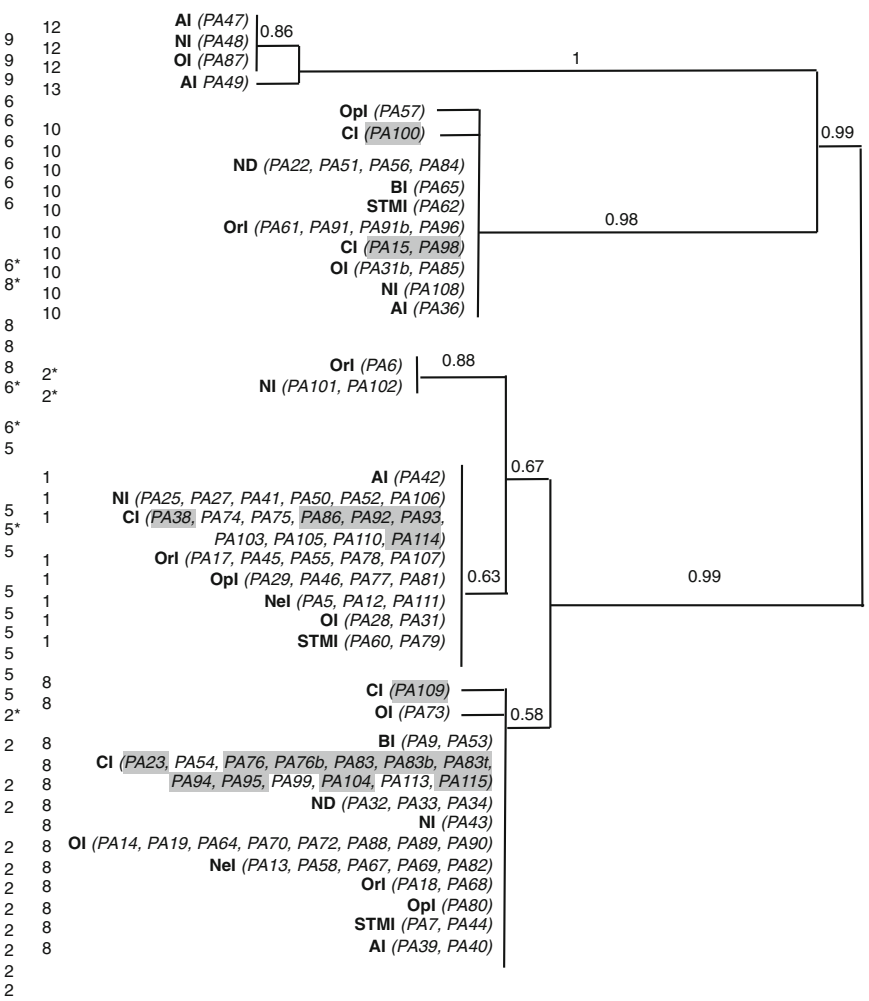

pubmlst.org/pacnes/. Allele numbers marked with an asterisk correspond to new alleles displaying $>99 \%$ identity in the sequence with the most related described allele. The numbers at the nodes are bootstrap values. Isolate names are in parentheses beside their clinical origin. Isolates from cardiac surgical site infections (SSI) origin are shaded 
Links between phylotypes and clinical origin

Phylotype I was largely the most prevalent in our collection focused on strains involved in deep or severe infections (from 67 to $100 \%$, depending on the clinical origin). Type II represented $19.2 \%$ of the collection and type III was represented by only three strains (Fig. 2). The distribution of clinical isolates by phylotypes appeared to be globally independent of their origin (Fig. 2). However, some particularities deserved to be underlined. Strains from the abdominal area and from orthopedic or neurological infections belonged to the four phylotypes IA, IA-2/IB, II, and III, and phylotype III was not detected from the other origins. On the contrary, the eight isolates from neonates, mostly from gastric liquid, belonged to type I. Phylotype IA was mainly found in head and neck infections, with $68 \%, 63 \%$, and $45 \%$ from ophthalmologic, neurological, and oropharyngeal origins, respectively. For all the other clinical origins, the genetic diversity of isolates was dominated by phylotype IA-2/IB. This is noteworthy for strains implicated in orthopedic surgery and bacteremia. Among the oropharyngeal strains included herein, type II was particularly prevalent (36.4\%). The distribution in phylotypes of the 27 isolates from cardiothoracic infections, also considering the strains from cardiac SSI separately, was roughly similar to that of the whole population (Fig. 2).

\section{Hemolytic phenotypes in clinical strains}

The repartition in phylotypes of the hemolytic behavior for the 99 isolates is presented in Fig. 3a. Non-hemolytic strains were distributed in the recA-tly phylotypes IA, IA-2/IB, II, and III. No strains in phylotype III and only 2 isolates among 18 in phylotype II were hemolytic. In contrast, phylotype I was weakly $(33.7 \%)$ or strongly hemolytic $(36.3 \%)$. Phylotypes IA and IA-2/IB displayed $61 \%$ and $78 \%$ hemolytic strains, respectively. Of note, strain PA49 corresponding to recA type IA and tly type III was non-hemolytic, as for other typical type III strains.

The hemolytic capacities appeared to be rather related to the phylotype but varied slightly according to the origin of infections (Fig. 3b, c, d). The distribution of cardiothoracic isolates was roughly similar to that of the whole population, except for a few strains, mainly of type IA-2/IB, which were more often non-hemolytic in cardiothoracic isolates (Fig. 3b). Of note, the six isolates from cardiac valves were nonhemolytic IA-2/IB or II types, whereas strains from sternal wounds were mostly hemolytic (10/11) (Table 1). Nonhemolytic IA strains were all isolated from pacemaker lodge or devices. Cardiothoracic and neurological IA strains were either non-hemolytic or strongly hemolytic (Fig. 3b, d). No obvious hemolytic phenotype was related to neurological infections. In orthopedics, phylotype IA-2/IB dominated and was always hemolytic but often weakly (Fig. 3c). The three strains from blood culture were strongly hemolytic.

\section{Identification of the main phylotypes by rec $A$ PCR-TTGE}

The denaturing gel PCR assay was based on the genetic diversity of the $3^{\prime}$ part of the recA gene, containing 13 polymorphic sites in a 333-bp fragment (Table 2). This method was applicable to complex microbiota without subculturing and allowed the direct detection of the main recA phylotypes in a single experiment, by comparison to a ladder (Fig. 4).
Fig. 2 Relative prevalence of the different phylotypes of $P$. acnes according to clinical origin

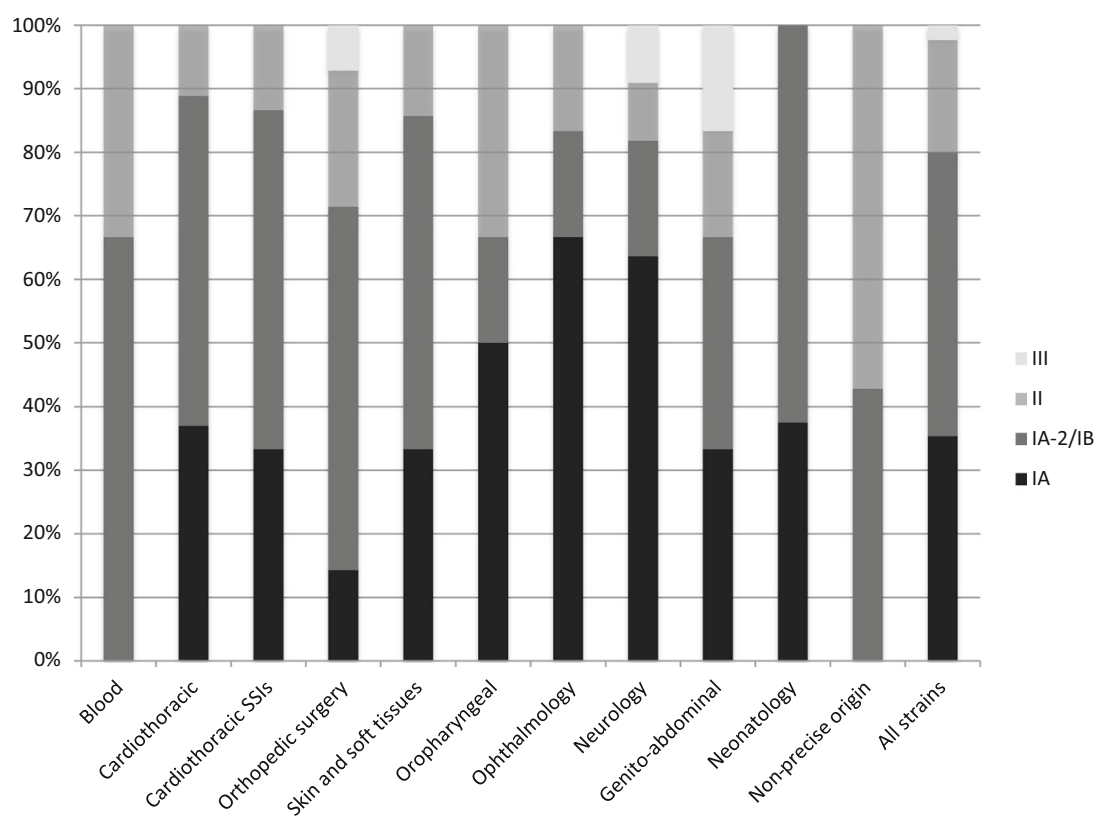



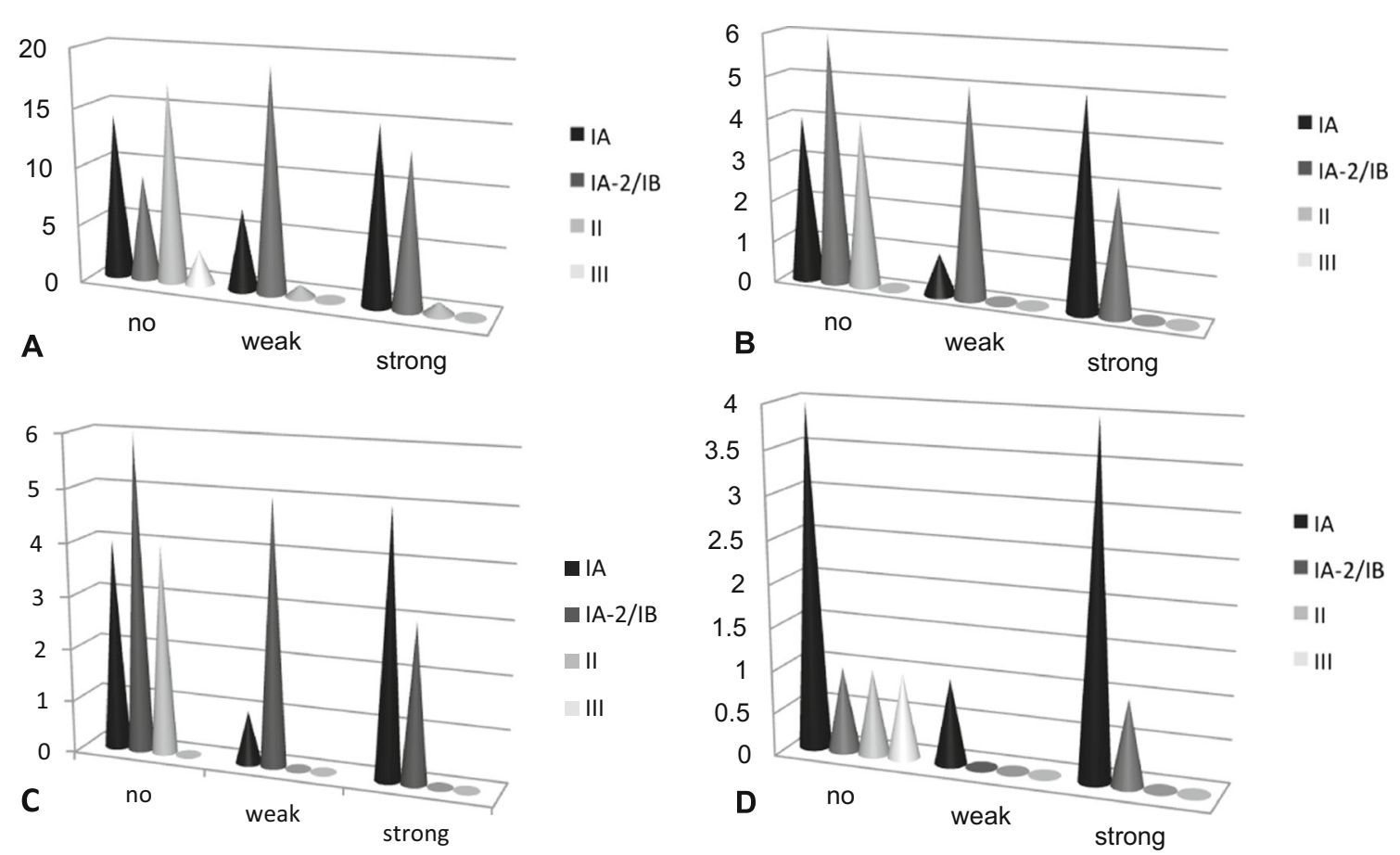

Fig. 3 Hemolytic phenotype according to the phylotype for: (a) the whole P. acnes population, (b) isolates from cardiothoracic infections, (c) isolates from orthopedic infections, and (d) isolates from neurological infections

Single nucleotide polymorphisms (SNP) in the $3^{\prime}$ part of the recA gene according to the types of sequence and the isolates are given in Table 2. Thirty-five of the 36 isolates belonging to phylotype IA shared an identical sequence type (IA-3'recA1). The strain PA55, remote from the other IA strains in the recA tree, displayed a T/C mutation in position 275 (IA-3'recA2), which conferred to the corresponding 333bp fragment a particular migration behavior in TTGE (Fig. 4). Almost all (41/42) of the type IA-2/IB strains shared the same allele (IA-2/IB-3'recA1). PA69 isolated from a neonatal gastric fluid was the sole strain with IA-2/IB-3'recA2 because of an SNP $(\mathrm{C} / \mathrm{A})$ in position 125. Despite a single SNP $(\mathrm{G} / \mathrm{A})$ in position 167 between IA-3'recA1 and IA-2/IB-3'recA1, they were clearly separated in TTGE (Fig. 4). The three clinical isolates PA47, 48, and 87 belonging to type III in the recA tree shared the same sequence type III-3'recA1 that migrated differentially from other ST. The type III-3'recA1 TTGE band displayed a fuzzy aspect compared to bands corresponding to the other phylotypes (Fig. 4).

As expected from the recA tree topology, phylotype II was more variable, with four different ST that roughly corresponded to the four branches in the tree (Fig. 1). Allele II-3'recA1 was shared by 13 of the 19 type II strains (Fig. 4), mostly grouped in the main cluster that contains the reference sequence of phylotype II in the recA tree (Fig. 1). Four clinical isolates presented the same II-3'recA2, differing from II-3' recA1 by one SNP (C/T in 98$)$. The three other type II clinical strains PA36, 37, and 57 in the external position in the recA tree (Fig. 1) displayed two different sequences (Fig. 4).
Finally, phylotype II displayed four migration profiles, each differing from the other phylotypes. The ten bands corresponding to ten $3^{\prime}$-recA types were included in a ladder to represent the recA PCR-TTGE diversity of our collection (Fig. 4).

\section{P. acnes phylotypes involved in cardiac surgery}

We obtained 154 superficial and deep samples from 14 patients during the different stages of hospitalization in cardiac surgery. Seventy samples were positive when they were screened for significant bacterial load using universal $16 \mathrm{~S}$ rRNA gene PCR. Therefore, these samples constituted the set for the direct detection of the $P$. acnes phylotypes by recA PCR-TTGE. Among them, 54 were collected during the surgical procedure, 34 superficially (19/34 and 15/34 cutaneous and subcutaneous samples, respectively) and 20 deeply (11/20 and 9/20 sternal edges and mediastinum samples, respectively). Seven samples concerned the skin before hospitalization, seven samples the skin and scar tissues after the surgical intervention, and only two samples involved the skin 3 months after the surgery. The TTGE fingerprints of ten representative samples are shown in Fig. 4. The phylotypes present in the 70 perioperative samples were identified by comparison to the diversity ladder. Four bands that did not match the ladder were separately analyzed and did not correspond to any known sequence type (data not shown).

The $P$. acnes phylotyping for all perioperative and peroperative samples from each patient is presented in Table 3 . 


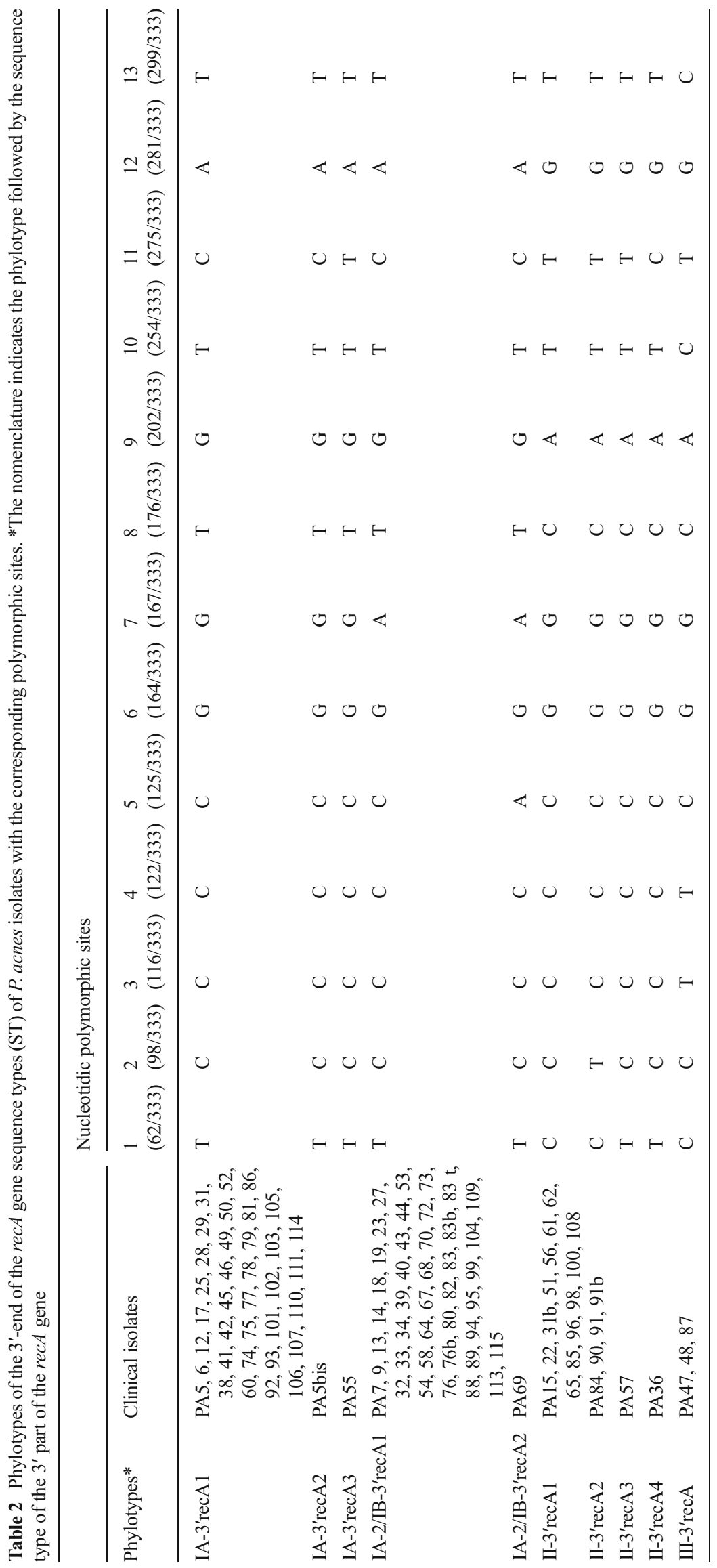


Fig. 4 rec $A$ polymerase chain reaction temporal temperature gel electrophoresis (PCR-TTGE) experiment showing the migration of strains representative of phylotypes IA, IB, II, and III and the migration of ten representative samples from patients in cardiac surgery. The four bands representative of the major 3 ' recA types are included in the ladder

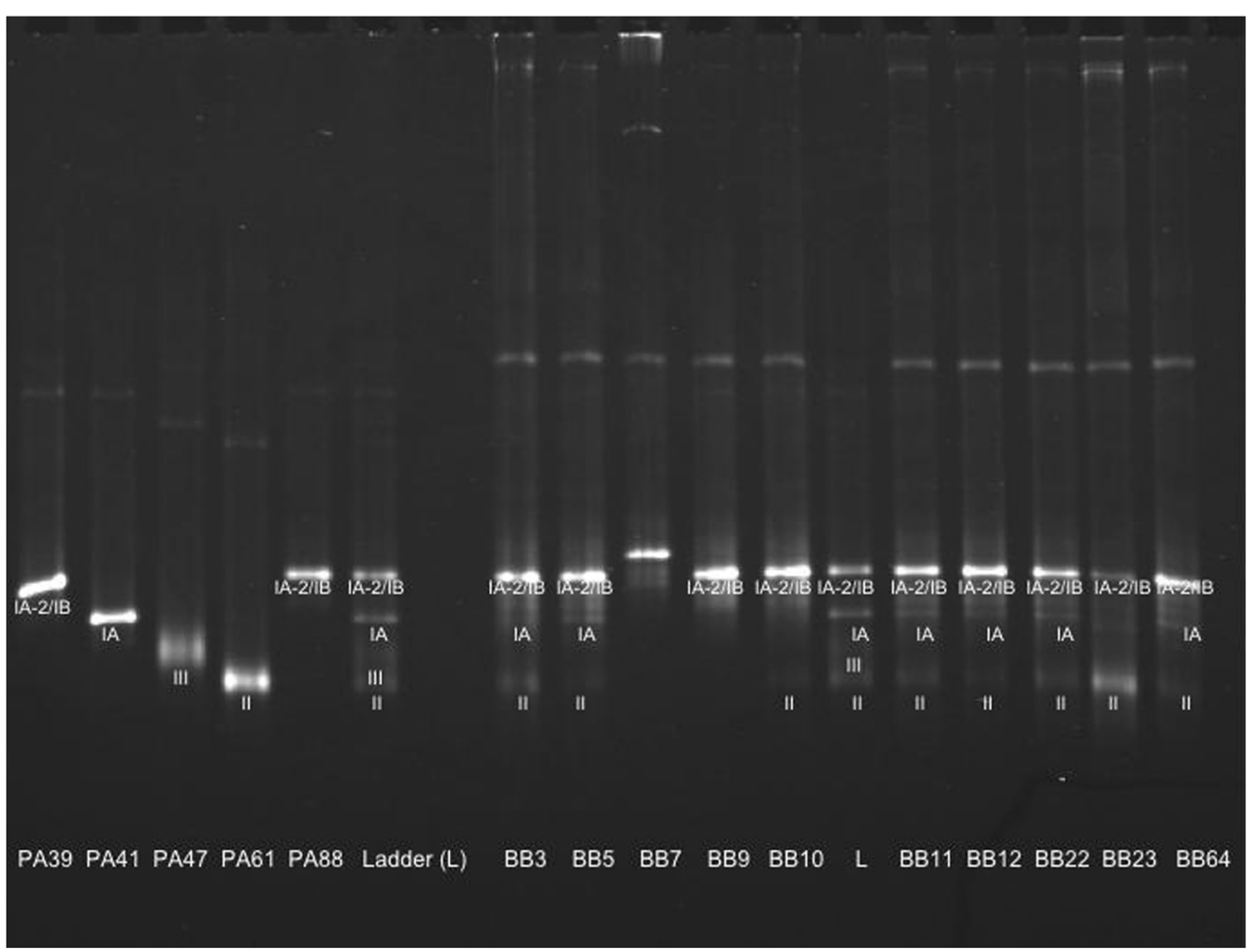

As previously described for clinical isolates, phylotype I predominated in surgical samples, with $32(46 \%)$ and $55(78 \%)$ samples sharing types IA and IA-2/IB, respectively, whereas phylotype III was found in only three samples (Table 3). Surprisingly, phylotype II was widely represented in surgical samples $(n=30,43 \%)$, principally in superficial and lowdepth samples (i.e., cutaneous and subcutaneous tissues). We observed major variations among patients, some of them presenting a wide diversity of $P$. acnes with three or four phylotypes during the hospitalization pathway (patients AQ

Table 3 Origins and characteristics of the samples collected during the hospitalization course of 14 patients in cardiac surgery. The empty cells correspond to negative samples in 16S rRNA gene polymerase chain and $\mathrm{AR}$, for example) and others with only one phylotype at only some stages of the surgery (patients $\mathrm{AB}$ and $\mathrm{AL}$ ) (Table 3).

The phylotype diversity curves according to the stage of surgery and hospitalization were constructed for the whole population of patients (Fig. 5). These curves represented the relative distribution of each $P$. acnes phylotype according to the surgical stage and depth of sampling in the surgical site. Despite high variability depending on the patient, the diversity curves showed common themes in the patient population and

reaction (PCR). The shaded cells show the detection of $P$. acnes phylotypes on samples with positive $16 \mathrm{~S}$ rRNA gene PCR

\begin{tabular}{|c|c|c|c|c|c|c|c|c|c|c|c|c|c|c|c|c|c|c|c|c|c|c|c|c|c|c|c|c|c|c|c|c|}
\hline \multirow{3}{*}{ 劳 } & \multirow{2}{*}{\multicolumn{3}{|c|}{$\begin{array}{l}\text { Preoperative } \\
\text { Cutaneous }\end{array}$}} & \multicolumn{12}{|c|}{ Beginning of the intervention } & \multicolumn{12}{|c|}{ End of the intervention } & \multicolumn{5}{|c|}{ Postoperative } \\
\hline & & & \multicolumn{4}{|c|}{$\begin{array}{l}\text { Cutaneous atter } \\
\text { antisepsy }\end{array}$} & \multicolumn{3}{|c|}{ Sub-cutaneous } & \multicolumn{3}{|c|}{ Strenal edges } & \multicolumn{3}{|c|}{ Mediastinum } & \multicolumn{3}{|c|}{ Mediastinum } & \multicolumn{3}{|c|}{ Strenal edges } & \multicolumn{3}{|c|}{ Sub-cutaneous } & \multicolumn{3}{|c|}{ Cutaneous } & \multicolumn{3}{|c|}{ Scar tissue } & \multicolumn{2}{|c|}{$\begin{array}{l}\text { Cutaneous } 3 \\
\text { months later }\end{array}$} \\
\hline & $\begin{array}{ll}\mathrm{IA} & \begin{array}{l}\mathrm{AA} 2 \\
\mathrm{AB}\end{array} \\
\end{array}$ & " " & IA & $\begin{array}{l}\mathrm{AA} 2 \\
\mathrm{AB} \\
\end{array}$ & " & & \begin{tabular}{l|l}
$\mathrm{AA}$ & $\begin{array}{l}\mathrm{AA} 2 \\
/ \mathrm{BB}\end{array}$ \\
\end{tabular} & $"$ & III & $\begin{array}{ll}1 \mathrm{~A} & \mathrm{AA} 2 \\
/ \mathrm{BB}\end{array}$ & $"$ & "II & $\begin{array}{ll}\mathrm{IA} & \begin{array}{l}\mathrm{AA} 2 \\
\mathrm{AB}\end{array} \\
\end{array}$ & " & "I' & ${ }_{1 A} \mid$\begin{tabular}{l|l}
$\mid A$ \\
11
\end{tabular} & $\begin{array}{ll}2 & \\
8 & \| \\
\end{array}$ & III & \begin{tabular}{|l|l}
$A$ & $1 A 2$ \\
$A B$
\end{tabular} & " & "I' & \begin{tabular}{l|l}
$A$ & $1 A 2$ \\
$A / B$
\end{tabular} & " & "II & \begin{tabular}{|l|l|}
$1 A$ & $1 A 2$ \\
& $A B$ \\
\end{tabular} & $"$ & III IA & \begin{tabular}{|l|l|}
$A \mathrm{~A} 2$ \\
$\mid{ }_{1 \mathrm{~B}}$
\end{tabular} & $\|$ & 1118 & \begin{tabular}{|l|l|}
$A$ & $\mid A 2$ \\
$A B B$
\end{tabular} & " "1" \\
\hline AB & & & & & & & & & & & & & & & & & & & & & & & & & & & & & . & & & \\
\hline$\overline{A C}$ & & & & & & & & $X$ & & & & & & & & & & & & & & & & & & & & & & & & \\
\hline AD & & & & & & & & & & & & & & & & & & & & X & & & & & & & & & & & & \\
\hline AF & & & & & & & & & & & & & & & & & & & & & & & & & & & & & 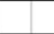 & & & \\
\hline$A G$ & & & & & & & & & & & X & & & & & & & & & & & & & & & & & & . & & & \\
\hline AL & & & & & & & & & & & & & & & & & & & & & & & & & & & & & & & & \\
\hline AM & & & & & & & & & & & & & & & & & & & & & & & & & & & & & & & & \\
\hline$A Q$ & & & & & & & & & & & & & & & & & & & & & & & & & & & & & & & & \\
\hline AR & & & & & & & & & & & & & & & & & & & & & & & & & & & & & & & & \\
\hline AW & & & & & & & & & & & & & & & & & & & & X & & & & & & & & & & & & \\
\hline$A x$ & & & & & & & & & & & & & & & & & & & & & & & & & & & & & & & & \\
\hline BB & & & & & & & & & & & & & & & & & & & & & & & & & & & & & & & & \\
\hline$B C$ & & & & & & & & & & & & & & & & & & & & & & & & & & - & & 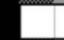 & 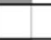 & & & \\
\hline$B D$ & & & & & & & & & & 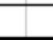 & & & 1 & & & & 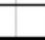 & & & 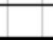 & & & & & & - & & & 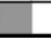 & & $\ldots$ & 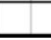 \\
\hline
\end{tabular}




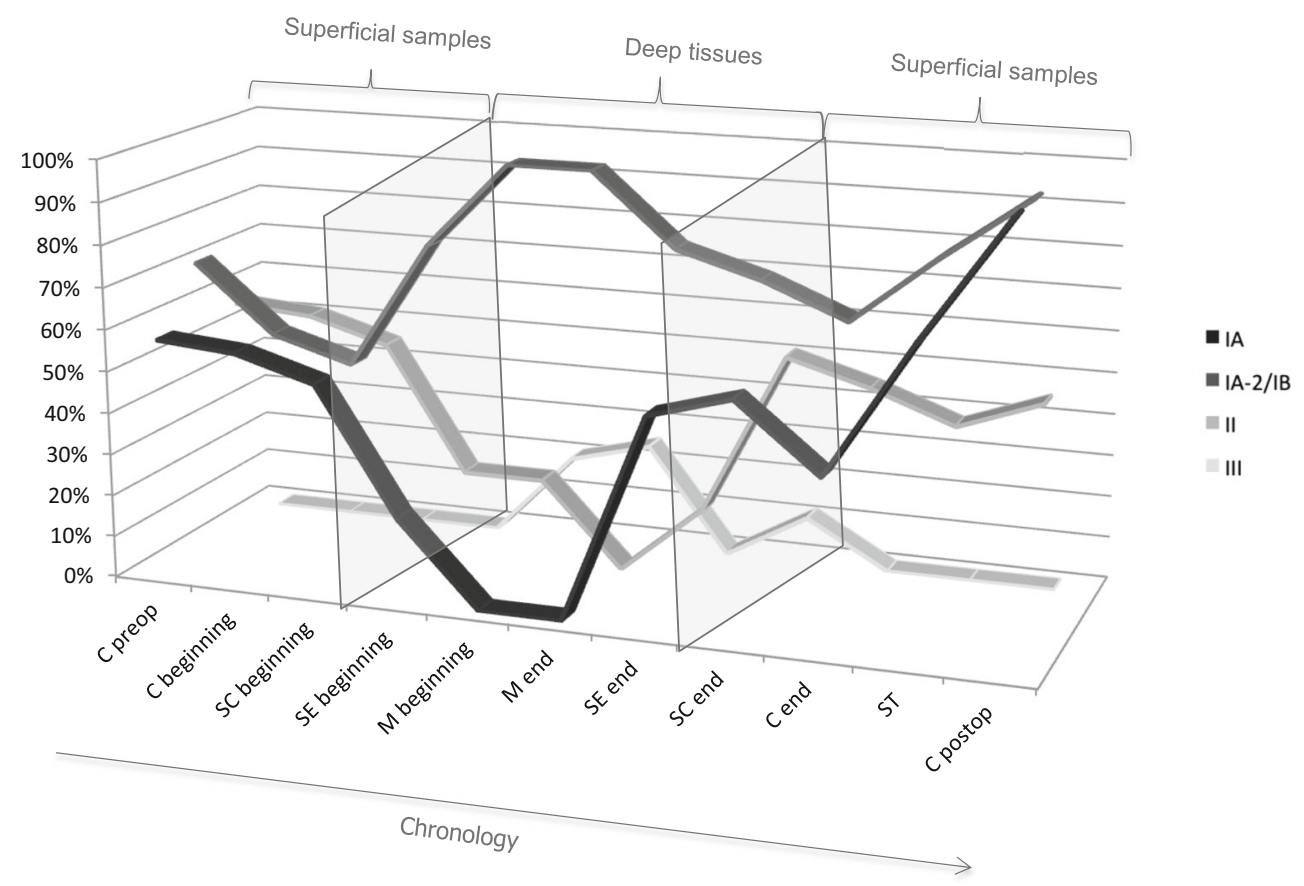

Fig. 5 Dynamics of the $P$. acnes phylotypes in samples chronologically collected during hospitalization and cardiac surgical procedures of 14 patients. The curves display the percentage of samples positive for each $P$. acnes phylotype according to the surgical stage and depth of sampling in the surgical site. $C$ preop preoperative cutaneous sample, $C$ cutaneous samples, $S C$ subcutaneous samples, $S E$ sternal edges samples, $M$ mediastinal samples, beginning at the beginning of the surgical intervention,

an interesting dynamics of the different phylotypes according to the depth of the wound and the step of surgical intervention (Fig. 5). Types IA and II displayed similar evolutions: they were present in superficial and low-deep tissues both at the beginning and at the end of the surgery, but they decreased in deep samples. Type IA greatly increased in postoperative samples such as scar tissues and in samples taken 3 months after surgery at a greater level than before surgery, while type II returned to its preoperative level. Type IA was also more present in sternal edges samples at the end than at the beginning of the intervention, suggesting peroperative colonization.

Type IA-2/IB presented an outstanding evolution, with a gradual increase with the depth of sampling, but also with the time of sampling in subcutaneous and cutaneous samples. This result suggested a particular resistance of phylotype IA2/IB to the antimicrobial agents used in perioperative prophylaxis. However, both $P$. acnes IA and IA-2/IB cardiothoracic isolates were susceptible to antibiotics used in perioperative prophylaxis: cefamandole, vancomycin, and clindamycin.

Despite its low prevalence, type III displayed an increase in deep mediastinal tissues and subcutaneous tissues at the core phase of the surgery, but disappeared in superficial samples. Phylotypes IA and IA-2/IB were both predominant in scar tissues and on postoperative skin a long time after intervention, suggesting a specific predisposition to recolonize skin. end at the end of the surgical intervention, $S T$ scar tissues, $C$ postop postoperative cutaneous samples ( 3 months postdischarge). Superficial samples correspond to cutaneous, subcutaneous, and scar tissues. Deeper samples correspond to sternal edges and mediastinal samples both at the beginning and at the end of the surgical procedure. The arrow represents the chronological course of patient hospitalization

\section{Discussion}

P. acnes is an usual member of healthy skin microbiota, often considered a good bacterium devoid of pathogenicity [25]. However, its role in inflammatory processes in acnes vulgaris and in several infections has been established [11,33-35]. In opposition to allopatric true pathogens, mutualistic bacteria are generally organized in species complex [36] and the comprehension of their opportunistic pathogenic behavior occurs through deciphering of the population structure inside the species complex. Most population genetic studies were focused on healthy skin and acne isolates, despite a wider the pathogenic spectrum of $P$. acnes. Deep or severe infections such as HAI were rarely studied, except for large collections of strains from failed hip replacements [26] and orthopedic implants [11]. Here, we aimed to determine if genetic subpopulations were specifically linked to specific sites or severe infections, as for the IA phylotype to acne. This hypothesis is supported by linkage disequilibrium analysis suggesting that the different phylogroups of $P$. acnes may occupy distinct ecological niches [25] and, therefore, may display different behaviors in different body sites. To meet our objective, we constituted a collection of natural isolates of $P$. acnes identified during severe infectious processes or from different origins in the routine exercise of hospital microbiology. The collection consisted mainly of strains from orthopedic and 
cardiothoracic surgeries, as well as head and neck infections. Our collection is also original owing to strains from origins rarely represented or unrepresented in previous studies: peritoneal dialysis, gastric fluid in neonates, and otolaryngologic samples.

Several studies have already analyzed the $P$. acnes population structure by different methods, based first on serotyping and biotyping [37] and later by multilocus genetics and genomics $[17,19,22,23,25,26]$. Comparative genomics based on 123,223 SNP nucleotides in the core regions highlighted that the $r e c A$ classification of the strains was consistent with the major genomic clades [25]. The gene tly also has a recognized typing power [23, 25, 26]. In previous studies on large populations, the recA and tly genes showed good phylogenetic discriminative power and high genetic diversity index $(0.67$ each), making them good genetic markers [20, 25]. Moreover, despite the use of only two genes, we gained in allele variability because we analyzed larger sequences than that in major MLST schemes (available in http://pacnes.mlst.net/ and http://pubmlst.org/pacnes/). Consequently, we found a greater genetic polymorphism than in other studies, with some polymorphic sites being present at the extremities of $r e c A$ and tly sequences not included in previously published studies. The high polymorphism in the 3' part of the recA gene met our second objective, which was to develop a rapid and efficient tool (recA PCR-TTGE) to identify the major P. acnes phylotypes in complex communities without a first step of isolation by culture. The primary stratification of the $P$. acnes populations performed herein would be used as a basis for downstream MLST analysis on selected strains or selected phylotypes potentially associated with a particular type of deep infection.

However, deep MLST analyses [25] underscored the lack of specificity of $r e c A$ due to the sharing of some type IB alleles with members of clonal complex 4 in phylotype IA-1 and with all type IA-2 members. Moreover, some tly alleles such as allele 8 were also shared between IA-2 and IB types [25]. Indeed, allele 8 is detected in $100 \%$ of IB isolates and $97 \%$ of IA-2 isolates [25]. In our phylogenetic tree, all the strains affiliated to the clade IA presented the tly allele 1. Therefore, considering the global congruence between the tly and recA trees, they certainly do not belong to IA-2 and probably corresponded to IA-1 isolates. For the alleles described herein, types IB and IA-2 could not be differentiated with certainty but type IA-2/IB differed clearly from type IA-1. The MLST schemes showed that IA-2 and IB underwent numerous recombination events involving most of the genes studies. Despite general linkage disequilibrium among phylotypes I, II, and III, the clonality of subtypes within phylotype I is less obvious. Particularly, IA-2 and IB phylotypes merged in split trees $[25,38]$ as the single clade named IA-2/IB with many parallelogram structures, indicating recombination events. The consequence is that lineages in phylotype I are not clearly separated; particularly, IA-2 and IB should be considered as an undifferentiated group IA-2/IB whatever the typing scheme considered because of the high level of allele recombinations.

In the collection tested, we did not show a strict correlation between origins of infection and phylotypes. While previous studies showed that phylotypes II and III were rarely present in skin samples [19, 22, 24], we highlight their higher prevalence in deep infection sites. To our knowledge, we describe for the first time among strains from oropharyngeal sphere that about $35 \%$ of them belong to type II. Not enough strains from blood cultures were included in this study but we observed a high prevalence of IA-2/IB and II. McDowell et al. [25] underlined the association of types IA-2/IB and II with medical devices, which are frequently the source of bacteremia in HAI. Both types IA and IA-2/IB are found in gastric fluids in neonatology. Therefore, we can hypothesize that the transmission from mother microbiota to newborn during delivery involves principally $P$. acnes type I.

As described previously [11], we found that phylotype I was the most often involved in orthopedic surgery, and type IA-2/IB (with 8 of the 12 isolates in the $r e c A$ tree) more frequently than IA. Considering the lack of discrimination of recA underlined by McDowell et al. in 2012 [25], one can say that orthopedic surgery isolates more often belong to type IA2/IB than to IA1. This was also the case for strains involved in cardiac SSI, unlike the data previously published by Davidsson et al. in 2012 [19], with a majority of type IA (only ten strains typed). These results suggest a particular tropism of type IA-2/IB for surgical wounds in orthopedic and cardiac surgeries, but not in neurosurgical infections, where phylotype IA was more often isolated.

Besides its genetic typing value, we studied the tly gene because it encodes a putative virulence factor that could be related to a particular pathogenic behavior. Except for three strains that probably encountered recombination events, tly and $r e c A$ markers give congruent population structures, suggesting that tly coevolve with housekeeping genes. In spite of the general role of hemolysins in bacterial pathogenesis, comparative genomics prove that tly belongs to the core genome of P. acnes [25], but not to island-like genomic regions, encoding a variety of traits that differ between phylotypes [39]. McDowell et al. [25] hypothesized the importance of tly for both mutualistic and pathogenic lifestyles. Brzuszkiewicz et al. [39] concluded that the virulence of different $P$. acnes strains is not only determined by the phylotype-specific genome content but also by variable gene expression. For instance, despite the presence of tly in the P. acnes core genome, all strains do not express a hemolytic phenotype [26]. Moreover, tly hemolysin is not the only putative virulence factor able to induce hemolysis; several others like the group of CAMP factors and other cytotoxins, known to have this ability, have been identified in the $P$. acnes genome $[4,40]$. 
Our results showed an interesting expression of hemolytic activity: the absence or very low hemolytic activity within phylotypes II and III, whereas about half of the IA strains and almost all IA-2/IB strains expressed hemolysis. Studies describing the hemolysis activities according to the genetic type in the $P$. acnes population are rare [41]. We found $70 \%$ of phylotype I strains to be hemolytic, suggesting a potential role of hemolysin activity in infectious processes occurring in deep tissues. Concerning phylotype II, acne strains and deeper infection strains display similar hemolytic behavior, with about $10 \%$ of hemolytic isolates in this study versus $12 \%$ in the population of acne strains described by Kasprowicz et al. [41]. Besides hemolysis, biofilm formation is a virulence mechanism with potential importance in HAI [42]. P. acnes biofilm allows a latent growth $[43,44]$ that could lead to lateonset deep infections like SSI on foreign materials in orthopedic surgery or in endocarditis and prosthetic valves in cardiac surgery $[8,9,11,35,43]$. No correlation has been yet found between phylotypes and biofilm production, as all phylotypes contain isolates with different levels of biofilm production [43]. However, in sebaceous follicles, P. acnes biofilms are predominantly composed of types IA and II strains [45].

Finally, as for most opportunistic pathogens originating in the host microbiota, the virulence of $P$. acnes is difficult to decipher. Members of complex microbiota, such as humanassociated microbiota, encounter complex relationships with host and other microbes. Therefore, the pathophysiology of the infection should take the microbiota dynamics into account as a major factor involved in infectious process. For this purpose, we propose a follow-up of the $P$. acnes diversity during the hospitalization courses of patients in cardiac surgery. Taking the opportunity for the high variability of the 3'terminal region of the recA gene (13 variable positions in $333 \mathrm{bp}$ ), we developed an original culture-independent approach, the recA PCR-TTGE. This approach appears suitable to survey $P$. acnes populations during cardiac surgery procedures, allowing rapid screening of the main phylotypes involved in several samples. Our results showed that different phylotypes coexist in the same sample. This finding, which presented a certain novelty, is difficult to achieve when the $P$. acnes detection is based on culture because culture-based methods request the isolation of one pure bacterial colony. Phylotype IA-2/IB seems to be particularly adapted to colonize deep sternal and thoracic tissues (both sternal edges and mediastinum), as well as scar tissues after surgery. Type II was also very present at the different steps of hospitalization except in deep tissues, and did not increase during surgical intervention. These behaviors seemed to be not linked to particular resistance to antimicrobial agents used in cardiac surgical prophylaxis.

This study highlights a particular adaptation of phylotype IA-2/IB to cardiac surgery, in both the wound surgical colonizing community and SSI. However, the strains isolated from cardiac SSI were obtained by cultural methods and did not reflect the whole $P$. acnes population initially involved in the sample. To confirm and complete the distribution scheme of $P$. acnes phylotypes in severe human infections, it would be necessary to increase the number of isolates from the different clinical sites and explore the dynamics of $P$. acnes phylotypes in diverse complex communities and their pathological variations. For this purpose, the specific culture-independent approach proposed herein would provide an efficient tool. Moreover, it also seems relevant to specify the phylotype(s) and/or the clonal complex (CC) present in surgical samples, thereafter to explore potential virulence characteristics involved in the pathophysiology of SSI.

Acknowledgments We thank Brigitte Lamy, Hélène Marchandin, and Anne-Laure Michon from the Bacteriology Laboratory of Montpellier Hospital for providing the clinical strains, and all the members of the cardiothoracic surgery team of Montpellier Hospital for the surgical samples collections. We also thank Valérie Macioce from Département d'Information Médicale of Montpellier Hospital for her help in reviewing the English language. This work was supported by a public grant from the French research ministry and by the association ADEREMPHA, Sauzet, France.

Conflict of interest The authors declare that they have no conflict of interest.

\section{References}

1. Delgado S, Suárez A, Mayo B (2011) Identification, typing and characterisation of Propionibacterium strains from healthy mucosa of the human stomach. Int J Food Microbiol 149:65-72

2. Whitman WB, Parte A, Goodfellow M, Kämpfer P, Busse H-J, Trujillo ME, Ludwig W, Suzuki K (2012) Bergey's manual of systematic bacteriology: volume 5: the actinobacteria. Springer, New York

3. Kunishima S, Inoue C, Kamiya T, Ozawa K (2001) Presence of Propionibacterium acnes in blood components. Transfusion 41: 1126-1129

4. Brüggemann H (2005) Insights in the pathogenic potential of Propionibacterium acnes from its complete genome. Semin Cutan Med Surg 24:67-72

5. Qin M, Pirouz A, Kim MH, Krutzik SR, Garbán HJ, Kim J (2014) Propionibacterium acnes induces IL-1 $\beta$ secretion via the NLRP3 inflammasome in human monocytes. J Invest Dermatol 134:381-388

6. Eishi Y (2013) Etiologic link between sarcoidosis and Propionibacterium acnes. Respir Investig 51:56-68

7. Hrbacek J, Urban M, Hamsikova E, Tachezy R, Heracek J (2013) Thirty years of research on infection and prostate cancer: no conclusive evidence for a link. A systematic review. Urol Oncol 31:951965

8. Noel W, Hammoudi N, Wegorowska E, D'Alessandro C, Steichen O (2012) Pacemaker endocarditis caused by Propionibacterium acnes: a case report. Heart Lung 41:e21-e23

9. Pan S-C, Wang J-T, Hsueh P-R, Chang S-C (2005) Endocarditis caused by Propionibacterium acnes: an easily ignored pathogen. J Infect 51:e229-e231 
10. Zedtwitz-Liebenstein K, Gabriel H, Graninger W (2003) Pacemaker endocarditis due to Propionibacterium acnes. Infection 31:184 185

11. Sampedro MF, Piper KE, McDowell A, Patrick S, Mandrekar JN, Rouse MS, Steckelberg JM, Patel R (2009) Species of Propionibacterium and Propionibacterium acnes phylotypes associated with orthopedic implants. Diagn Microbiol Infect Dis 64:138145

12. Berthelot P, Carricajo A, Aubert G, Akhavan H, Gazielly D, Lucht F (2006) Outbreak of postoperative shoulder arthritis due to Propionibacterium acnes infection in nondebilitated patients. Infect Control Hosp Epidemiol 27:987-990

13. Unemo M, Friberg O, Enquist E, Källman J, Söderquist B (2007) Genetic homogeneity/heterogeneity of Propionibacterium acnes isolated from patients during cardiothoracic reoperation. Anaerobe 13: $121-126$

14. Jakab E, Zbinden R, Gubler J, Ruef C, von Graevenitz A, Krause M (1996) Severe infections caused by Propionibacterium acnes: an underestimated pathogen in late postoperative infections. Yale $\mathrm{J}$ Biol Med 69:477-482

15. Sampedro MF, Huddleston PM, Piper KE, Karau MJ, Dekutoski MB, Yaszemski MJ, Currier BL, Mandrekar JN, Osmon DR, McDowell A, Patrick S, Steckelberg JM, Patel R (2010) A biofilm approach to detect bacteria on removed spinal implants. Spine (Phila Pa 1976) 35: $1218-1224$

16. Fitz-Gibbon S, Tomida S, Chiu B-H, Nguyen L, Du C, Liu M, Elashoff D, Erfe MC, Loncaric A, Kim J, Modlin RL, Miller JF, Sodergren E, Craft N, Weinstock GM, Li H (2013) Propionibacterium acnes strain populations in the human skin microbiome associated with acne. J Invest Dermatol 133:2152-2160

17. Tomida S, Nguyen L, Chiu B-H, Liu J, Sodergren E, Weinstock GM, Li H (2013) Pan-genome and comparative genome analyses of Propionibacterium acnes reveal its genomic diversity in the healthy and diseased human skin microbiome. MBio 4:e00003-13

18. Kasimatis G, Fitz-Gibbon S, Tomida S, Wong M, Li H (2013) Analysis of complete genomes of Propionibacterium acnes reveals a novel plasmid and increased pseudogenes in an acne associated strain. Biomed Res Inter 2013:918320

19. Davidsson S, Söderquist B, Elgh F, Olsson J, Andrén O, Unemo M, Mölling P (2012) Multilocus sequence typing and repetitivesequence-based PCR (DiversiLab) for molecular epidemiological characterization of Propionibacterium acnes isolates of heterogeneous origin. Anaerobe 18:392-399

20. Kilian M, Scholz CF, Lomholt HB (2012) Multilocus sequence typing and phylogenetic analysis of Propionibacterium acnes. J Clin Microbiol 50:1158-1165

21. McDowell A, Gao A, Barnard E, Fink C, Murray PI, Dowson CG, Nagy I, Lambert PA, Patrick S (2011) A novel multilocus sequence typing scheme for the opportunistic pathogen Propionibacterium acnes and characterization of type I cell surface-associated antigens. Microbiology 157:1990-2003

22. Lomholt HB, Kilian M (2010) Population genetic analysis of Propionibacterium acnes identifies a subpopulation and epidemic clones associated with acne. PLoS One 5:e12277

23. McDowell A, Perry AL, Lambert PA, Patrick S (2008) A new phylogenetic group of Propionibacterium acnes. J Med Microbiol 57:218-224

24. Niazi SA, Clarke D, Do T, Gilbert SC, Mannocci F, Beighton D (2010) Propionibacterium acnes and Staphylococcus epidermidis isolated from refractory endodontic lesions are opportunistic pathogens. J Clin Microbiol 48:3859-3869

25. McDowell A, Barnard E, Nagy I, Gao A, Tomida S, Li H, Eady A, Cove J, Nord CE, Patrick S (2012) An expanded multilocus sequence typing scheme for Propionibacterium acnes: investigation of 'pathogenic', 'commensal' and antibiotic resistant strains. PLoS One 7: e41480
26. McDowell A, Valanne S, Ramage G, Tunney MM, Glenn JV, McLorinan GC, Bhatia A, Maisonneuve J-F, Lodes M, Persing DH, Patrick S (2005) Propionibacterium acnes types I and II represent phylogenetically distinct groups. J Clin Microbiol 43:326-334

27. Nagy E, Urbán E, Becker S, Kostrzewa M, Vörös A, Hunyadkürti J, Nagy I (2013) MALDI-TOF MS fingerprinting facilitates rapid discrimination of phylotypes I, II and III of Propionibacterium acnes. Anaerobe 20:20-26

28. Kwon HH, Yoon JY, Park SY, Suh DH (2013) Analysis of distribution patterns of Propionibacterium acnes phylotypes and Peptostreptococcus species from acne lesions. Br J Dermatol 169: 1152-1155

29. Mak TN, Yu S-H, De Marzo AM, Brüggemann H, Sfanos KS (2013) Multilocus sequence typing (MLST) analysis of Propionibacterium acnes isolates from radical prostatectomy specimens. Prostate 73 : 770-777

30. Shannon BA, Cohen RJ, Garrett KL (2006) Polymerase chain reaction-based identification of Propionibacterium acnes types isolated from the male urinary tract: evaluation of adolescents, normal adults and men with prostatic pathology. BJU Int 98:388-392

31. Romano-Bertrand S, Parer S, Lotthé A, Colson P, Albat B, JumasBilak E (2012) Temporal temperature gel electrophoresis to survey pathogenic bacterial communities: the case of surgical site infections. In: Magdeldin S (ed) Gel electrophoresis - advanced techniques. InTech, pp 291-312

32. Tammelin A, Hambraeus A, Ståhle E (2002) Mediastinitis after cardiac surgery: improvement of bacteriological diagnosis by use of multiple tissue samples and strain typing. J Clin Microbiol 40:29362941

33. Saleh K, Sonesson A, Persson B, Riesbeck K, Schmidtchen A (2011) A descriptive study of bacterial load of full-thickness surgical wounds in dermatologic surgery. Dermatol Surg 37:1014-1022

34. Dessinioti C, Katsambas AD (2010) The role of Propionibacterium acnes in acne pathogenesis: facts and controversies. Clin Dermatol 28:2-7

35. Farrar MD, Ingham E (2004) Acne: inflammation. Clin Dermatol 22: 380-384

36. Georgiades K, Raoult D (2010) Defining pathogenic bacterial species in the genomic era. Front Microbiol 1:151

37. Kishishita M, Ushijima T, Ozaki Y, Ito Y (1980) New medium for isolating propionibacteria and its application to assay of normal flora of human facial skin. Appl Environ Microbiol 40:1100-1105

38. McDowell A, Patrick S, Eishi Y, Lambert P, Eady A (2013) Propionibacterium acnes in human health and disease. Biomed Res Int 2013:493564

39. Brzuszkiewicz E, Weiner J, Wollherr A, Thürmer A, Hüpeden J, Lomholt HB, Kilian M, Gottschalk G, Daniel R, Mollenkopf H-J, Meyer TF, Brüggemann H (2011) Comparative genomics and transcriptomics of Propionibacterium acnes. PLoS One 6:e21581

40. Valanne S, McDowell A, Ramage G, Tunney MM, Einarsson GG, O'Hagan S, Wisdom GB, Fairley D, Bhatia A, Maisonneuve J-F, Lodes M, Persing DH, Patrick S (2005) CAMP factor homologues in Propionibacterium acnes: a new protein family differentially expressed by types I and II. Microbiology 151:1369-1379

41. Kasprowicz A, Owczarek MM, Miedzobrodzki J, Białecka A (2012) A comparison of biochemical and genetic classification of Propionibacterium acnes strains isolated from skin lesions of patients with acne. Med Dosw Mikrobiol 64:203-210

42. Ziebuhr W, Hennig S, Eckart M, Kränzler H, Batzilla C, Kozitskaya S (2006) Nosocomial infections by Staphylococcus epidermidis: how a commensal bacterium turns into a pathogen. Int $\mathrm{J}$ Antimicrob Agents 28(Suppl1):S14-S20

43. Holmberg A, Lood R, Mörgelin M, Söderquist B, Holst E, Collin M, Christensson B, Rasmussen M (2009) Biofilm formation by Propionibacterium acnes is a characteristic of invasive isolates. Clin Microbiol Infect 15:787-795 
44. Coenye T, Peeters E, Nelis HJ (2007) Biofilm formation by Propionibacterium acnes is associated with increased resistance to antimicrobial agents and increased production of putative virulence factors. Res Microbiol 158:386-392
45. Jahns AC, Lundskog B, Ganceviciene R, Palmer RH, Golovleva I, Zouboulis CC, McDowell A, Patrick S, Alexeyev O (2012) An increased incidence of Propionibacterium acnes biofilms in acne vulgaris: a case-control study. Br J Dermatol 167:50-58 